International Journal of Current Advanced Research

ISSN: O: 2319-6475, ISSN: P: 2319 - 6505, Impact Factor: SJIF: 5.995

Available Online at www.journalijcar.org

Volume 6; Issue 4; April 2017; Page No. 3254-3256

DOI: http://dx.doi.org/10.24327/ijcar.2017.3256.0238

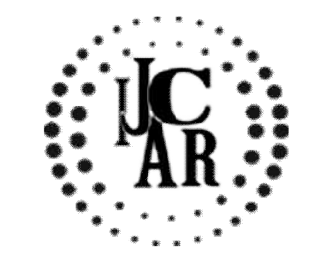

Research Article

\title{
IMAGING OF INTRACRANIAL SPACE OCCUPYING LESIONS: A PROSPECTIVE STUDY IN A TERTIARY CARE CENTRE IN NORTHERN WESTERN RAJASTHAN
}

\author{
Jagdish Prasadi', Deepika Meena $^{2}$., Deepak Meena ${ }^{3}$, , Manish Kumar Meena ${ }^{4}$ and G L Meena $^{5}$ \\ 1,5Department of Radiodiagnosis, SP Medical College \& Associate Group of PBM Hospitals, Bikaner \\ ${ }^{2}$ Rajasthan Dental College, Jaipur \\ ${ }^{3}$ Mahatama Gandhi Dental College Jaipur \\ ${ }^{4}$ S.N. Medical College, Jaipur
}

\section{A R T I C L E I N F O}

Article History:

Received $11^{\text {th }}$ January, 2017

Received in revised form $19^{\text {th }}$ February, 2017

Accepted $22^{\text {nd }}$ March, 2017

Published online $28^{\text {th }}$ April, 2017

Key words:

Brain, Tumefactive demyelination, Tumors

\begin{abstract}
A B S T R A C T
Introduction: During the last few years, the role of magnetic resonance imaging (MRI) as a diagnostic tool in neuroradiology is well-established. With advanced MRI techniques such as perfusion, diffusion, and spectroscopy, it is now possible to differentiate between various intracranial lesions.

Materials and Methods: This prospective cohort study was conducted from October 2015 to June 2016 \& included 50 patients referred by various clinical departments with clinical suspicion of intracranial space occupying lesions, evaluated by computed tomography \& magnetic resonance imaging. After taking informed consent, a detailed clinical history was recorded of each patient \& relevant clinical examination was done.

Result: Out of total 50patients enrolled for study most patients were in age range of 31 50 years \& the mean age was 42.2 years. $31(62 \%)$ patients were male \& $19(38 \%)$ patients were females. The main presenting symptoms were headache in 28 patients $(56 \%)$, loss of consciousness in 16 patients (32\%), 6 patients (12\%) each were having seizure \& vomiting. The most common clinical signs were altered sensorium in 22patients $(44 \%)$, behavioural changes in 16 patients (32\%) \& visual field defects in 12 patients $(24 \%)$.

Conclusion: Intracranial space occupying lesions comprise of a diverse group of lesions. With the introduction of CT \& MRI scanning, imaging of lesions has acquired a new dimension whereby excellent anatomical detail in axial, sagittal \& coronal planes as well as lesion characterization has become possible.
\end{abstract}

Copyright $@ 2017$ Jagdish Prasad et al. This is an open access article distributed under the Creative Commons Attribution License, which permits unrestricted use, distribution, and reproduction in any medium, provided the original work is properly cited.

\section{INTRODUCTION}

Distributions of tumor types vary substantially by age group and among the developing/developed countries. Data from several national cancer registries support differences in the epidemiology of brain tumors in children versus adults. High-grade glioma (30.5\%) and meningioma (29.4\%) are the most common types of adult primary brain tumors (data taken from the Swedish cancer registry). Males also generally have higher rates of primary malignant brain tumors while females have higher rates of non-malignant tumors, primary meningiomas. ${ }^{1}$ During the last few years, the role of magnetic resonance imaging (MRI) as a diagnostic tool in neuroradiology is well-established. With advanced MRI techniques such as perfusion, diffusion, and spectroscopy, it is now possible to differentiate between various intracranial lesions. The differential diagnosis of intra cerebral necrotic tumors and the cerebral abscess is frequently difficult on

*Corresponding author: Jagdish Prasad

Department of Radiodiagnosis, SP Medical College \&

Associate Group of PBM Hospitals, Bikaner conventional MRI as both can present as ring enhancing lesions. $^{2}$ The necrotic component of brain tumor (glioblastoma multiforme [GBM] and metastases) show marked hypo intensity on diffusion-weighted image (DWI) due to increased free water. The DWI must allow differentiation between necrotic tumors and cerebral abscess. ${ }^{3}$ The diffusion restricted signal helps in glioma grading on the basis of increasing tumor cellularity. Magnetic resonance spectroscopy (MRS) is highly sensitive in differentiating lowgrade from high-grade gliomas, perilesional tumor infiltration and more specific in characterizing abscess with lipid/lactate, amino acid peaks. Provides additional information over conventional study to differentiate extra axial tumors as meningeoma with alanine peak. Not only the common tumors are well-differentiated by MRI, but also space occupying lesions (SOL) of infective etiology, rare tumors, tumor mimicks as tumefactive demyelinating lesions and congenital lesions prevalence and imaging features are diagnosed by MRI. $^{4}$ 


\section{MATERIALS AND METHODS}

This prospective cohort study was conducted from October 2015 to June 2016 \& included 50 patients referred by various clinical departments with clinical suspicion of intracranial space occupying lesions, evaluated by computed tomography \& magnetic resonance imaging. After taking informed consent, a detailed clinical history was recorded of each patient $\&$ relevant clinical examination was done.

\section{Inclusion criteria}

- $\quad$ Presence of ICSOL on neuroimaging (CT/MRI).

- Exclusion criteria

- Traumatic \& non traumatic intracranial hematoma,

- Infarct \& demyelinating lesions,

- Lesion size less than $2 \mathrm{cms}$

- Bony lesions of skull

\section{METHODS}

Requested neuroimaging was done with prior explanation of the radiological investigation $\&$ informed written consent of the patient/relatives. CT was performed on Philips ingenuity core 128 multislice unit with axial, coronal and sagittal reconstructions of desired thickness of acquired data. CECT scans were performed after bolus injection of low osmolalaity non ionic iodinated contrast material. MRI scans were performed on 1.5T GE signa HDe 8 channel unit with acquisition of spin echo T1, T2, T2 Flair, SWI in desired planes and axial EPI- DWI \& ADC maps. CEMRI was done post IV gadolinium (dose $0.1 \mathrm{mmol} / \mathrm{kg}$ ) injection with acquisition of TIW scans in three orthogonal planes. Imaging findings were evaluated \& tabulated \& correlated with the clinical findings \& histopathological findings (wherever available) subsequently.

\section{Data analysis}

Data were initially summarized into means, standard deviations (SD); mean $\pm \mathrm{SD}$ and percentages in a form of comparison tables and graphs.

\section{RESULTS}

Out of total 50patients enrolled for study most patients were in age range of $31-50$ years \& the mean age was 42.2 years. $31(62 \%)$ patients were male \& 19 (38\%) patients were females. The main presenting symptoms were headache in 28 patients $(56 \%)$, loss of consciousness in 16 patients $(32 \%), 6$ patients $(12 \%)$ each were having seizure \& vomiting. The most common clinical signs were altered sensorium in 22 patients $(44 \%)$, behavioural changes in 16 patients $(32 \%) \&$ visual field defects in 12 patients $(24 \%)$.

Solitary lesions were present in 35 patients (70\%) \& multiple lesions in 15 patients (30\%). 70\% lesions were supratentorial \& $30 \%$ infratentorial in location. Most common supratentorial location in adults was frontal lobe $40 \%$ followed by parietal lobe $30 \%$. Most common supratentorial locations in children were frontal lob. Infratentorially, cerebellum \& posterior fossa were found to be most common location in adults \& children respectively. Supratentorial lesions were most common both in adults \& children. $60 \%$ lesions were intraaxial \& $40 \%$ extra axial in location. In adults, intraaxial lesions were more common than in children.
$70 \%$ patients were having neoplastic lesions \& $30 \%$ patients had non-neoplastic lesions. Neoplastic lesions included metastases 20\%, Astrocytomas 14\%, Meningiomas 10\%, Pituitary adenoma $10 \%$, Glial tumors $6 \%$, Schwannomas $4 \%$, Hemangioblastomas $2 \%$, Oligodendrogliomas $2 \% \quad \&$ Craniopharyngioma $2 \%$ whereas Non-Neoplastic lesion included Arachnoid cysts 10\%, Abscesses 8\%, Hydatid cysts $6 \%$, Tuberculoma 4\% \& Cavernoma $2 \%$.

CECT was done in 40 patients, out of which majority $(60 \%)$ were having hypodense lesions \& most common associated finding was mass effect $(80 \%)$. CECT was done in 10 patients out of which 8 patients $(80 \%)$ were having ring like pattern of enhancement. Unenhanced MRI, was done in 50 patients and majority of the lesions appeared hypointense on T1WI (70\%), hyperintense on T2WI $(70 \%)$ \& hyperintense on FLAIR $(30 \%)$ sequences with mass effect $(70 \%)$ as most common associated findings.

\section{DISCUSSION}

The term ICSOL is generally used to identify any lesion whether neoplastic or inflammatory in origin which increases the volume of intracranial contents \& leads to a rise in intracranial tension (ICT). The presentation of ICSOL has changed radically with increased availability of modern imaging techniques like CT \& MRI.The age ranges from 1-90 yrs in present study. The peak incidence was in 5th decade followed by 3 rd decade with male predominance was correlated with Madan $\mathrm{AH}$ et al study ${ }^{5}$.

In most of the cases in our study, more than one symptoms \& signs were present. The commonest symptom was headache $56 \%$. The similar observation was seen in study by Benjarge PV \& Kulkarni ${ }^{6}$ in which 55 patients had headache out of 80 patients and by Mahmoud $\mathrm{MZ}^{7}$ in which $43 \%$ patients presented with headache. The second most common presenting complaint in our study was loss of consciousness in $32 \%$ whereas $16.2 \%$ \& $14 \%$ patients in Benjarge PV \& Kulkarni $\mathrm{A}^{6}$ \& Mollah N et al study ${ }^{8}$ respectively had similar complaints. In our study, $12 \%$ patients were having seizure $\&$ vomiting. Seizures \& vomiting were the third commonest symptom observed in $46.25 \%$ out of 80 patients in Benjarge $\mathrm{PV} \&$ Kulkarni A study ${ }^{6}$ whereas Mollah $\mathrm{N}$ et al found vomiting in $52 \%$ \& seizures in $36 \%^{8}$

The most common clinical signs was altered sensorium in 44 $\%$ which was high as compared to Mollah N et al study ${ }^{8}$, only $6 \%$ had altered sensorium. The second most common presenting sign in our study was behavioural changes in $32 \%$, which was high as compared to Benjarge PV \& Kulkarni A study ${ }^{6}$ abnormal behaviour was observed in $8.75 \%$ cases. In our study, $70 \%$ lesions were supratentorial \& $30 \%$ infratentorial in location, which were corresponding to study by Chander $\mathrm{R}$ et al ${ }^{9}$, having $79 \%$ supratentorial \& $21 \%$ infratentorial lesions. Supratentorial was most common location both for adults \& children.

\section{CONCLUSION}

Intracranial space occupying lesions comprise of a diverse group of lesions. With the introduction of CT \& MRI scanning, imaging of lesions has acquired a new dimension whereby excellent anatomical detail in axial, sagittal \& coronal planes as well as lesion characterization has become possible. 
Funding: No funding sources

Conflict of interest: None declared

Ethical approval: The study was approved by theInstitutional Ethics Committee

\section{References}

1. Bondy ML, Scheurer ME, Malmer B, Barnholtz-Sloan JS, Davis FG, Il'yasova D, et al. Brain tumor epidemiology: Consensus from the brain tumor epidemiology consortium. Cancer 2008; 1137 Suppl: 1953-68.

2. Al-Okaili RN, Krejza J, Wang S, Woo JH, Melhem ER. Advanced MR imaging techniques in the diagnosis of intraaxial brain tumors in adults. Radiographics 2006; 26 Suppl 1:S173-89.

3. Gigineishvili D, Gigineishvili T, Tsiskaridze A, Shakarishvili R. Incidence rates of the primary brain tumours in Georgia- A population-based study. BMC Neurol 2014; 14:29.
4. Larjavaara S, Mäntylä R, Salminen T, Haapasalo H, Raitanen J, Jääskeläinen $\mathrm{J}$, et al. Incidence of gliomas by anatomic location. Neuro Oncol 2007; 9:319-25.

5. Madan AH, Chaurasia SB, Wankhede KU, Kumre DG. Clinical study of intracranial space occupying lesions $\&$ its ophthalmic manifestations. International Journal of Recent Trends in Science \& Technology 2015; 14(1):127-30. doi: 06.02.2015.

6. Benjarge PV, Kulkarni A: Clinical profile of intracranial space occupying lesions of the brain. MedPulse - International Medical Journal 2014; 1(6):288-92. doi:20.06.2014.

7. Mahmoud MZ. Intra Cranial Space Occupying Lesions In Saudi Patients Using Computed Tomography. Asian J Med Radiol Res 2013; 1(1):25-8. Available from: http://www.researchgate.net/publication/236869508

8. Mollah N, Baki A, Afzal N, Hossen A. Clinical \& Pathological Characteristics of Brain Tumor. BSMMU $J$ 2010; 3(2):68-71.

9. Available from: http://www.ijoimr.com/siteadmin/ article_issue/14369567382_Bipin\%20chavda_Patho.pd f.

\section{How to cite this article:}

Jagdish Prasad et al (2017) ' Imaging Of Intracranial Space Occupying Lesions: A Prospective Study In A Tertiary Care Centre In Northern Western Rajasthan', International Journal of Current Advanced Research, 06(04), pp. 3254-3256.

DOI: http://dx.doi.org/10.24327/ijcar.2017.3256.0238 